\title{
RELATIONSHIP BETWEEN RAILWAY STATIONS AND THE TERRITORY: CASE STUDY IN LOMBARDY - ITALY FOR 15-MIN STATION
}

\author{
FABIO BORGHETTI ${ }^{1}$, MICHELA LONGO ${ }^{2}$, RENATO MAZZONCINI ${ }^{3}$, CLAUDIO SOMASCHINI ${ }^{4}$, \\ LEONARDO CESARINI $^{5} \&$ LUIGI CONTESTABILE 6 \\ ${ }^{1}$ Politecnico di Milano, Design Department, Mobility and Transport Laboratory, Italy \\ ${ }^{2}$ Politecnico di Milano, Department of Energy, Italy \\ ${ }^{3}$ CEO of A2A S.p.A., Italy \\ ${ }^{4}$ Politecnico di Milano, Department of Mechanical Engineering, Italy \\ ${ }^{5}$ CCO of TRENORD S.r.L., Italy \\ ${ }^{6}$ Rete Ferroviaria Italiana S.p.A., Italy
}

\begin{abstract}
In Europe, urban areas represent the "engine" of economic growth and employment in a territory: about 85\% of the EU's GDP (gross domestic product) is generated in European cities. Several European cities, due to the extensive economic activities in urban areas, have to deal with and manage issues related to or caused by transport and mobility such as congestion, air pollution, safety and noise pollution. In 2010, for example, about $73 \%$ of European citizens lived in urban areas; this percentage is estimated to increase to more than $80 \%$ by 2050 . In addition to the direct impact generated by traffic, urban mobility can also influence social development, social exclusion, and accessibility for people with reduced mobility. Consequently, the need to adopt sustainable transport systems is now a global goal that can no longer be postponed. To promote sustainable mobility models, current planning strategies have used smart growth interventions to move from mono-centric city structures to poly-centric, more localized configurations. For example, the idea of the 15-minute city is gradually growing in importance from both a policy and social perspective. The basis of the idea is the promotion of interventions to increase the supply of local services, such as schools, public transportation systems, health care facilities, dining facilities, jobs, recreation areas, and retail stores. In this way, local areas are created that are sustainable, inclusive, and walkable within a small radius on foot or by bicycle. Starting from these considerations, the aim of this work is to apply the idea of the city in 15 min to railway stations: in this perspective, the railway station becomes the starting point of the analysis as it represents the "door of the house", from where users start their last mile trips after getting off the train.

For some railway stations located in northern Italy, an analytical index has been defined that summarizes the characteristics of the station in relation to the territory in which it is located. In this way, it is possible to classify the stations on the one hand and, on the other, to identify and propose improvements aimed at relaunching the role of a railway station in a territory.

Keywords: 15-minute city, 15-minute stations, environmental sustainability, GIS, mobility, railway station, smart mobility, transportation planning, transportation, urban mobility.
\end{abstract}

\section{INTRODUCTION}

In Europe, urban areas represent the "engine" of economic growth and employment in a territory: about $85 \%$ of the EU's GDP (gross domestic product) is generated in European cities. Several European cities, due to the extensive economic activities in urban areas, have to deal with and manage issues related to or caused by transport and mobility such as congestion, air pollution, safety and noise pollution. In 2010, for example, about $73 \%$ of European citizens lived in urban areas; this percentage is estimated to increase to more than $80 \%$ by 2050 [1]. In addition to the direct impact generated by traffic, urban mobility can also influence social development, social exclusion, and accessibility for people with reduced mobility. Consequently, the need to adopt sustainable transport systems is now a global goal that can no longer be postponed. 
Urban sprawl, observed in several countries around the world, is now considered harmful to the livability and sustainability of the city: this situation causes some externalities, including longer trips within the city, increased private car use, congestion and pollution [2-6]. Several studies have addressed the relationship between mobility within cities and urban design, giving rise to a debate on the optimal size and structure of cities [7-10]. To promote sustainable mobility models, current planning strategies have used smart growth interventions to move from mono-centric city structures to poly-centric, more localized configurations $[11,12]$. Strategies that promote polycentricity aim to increase the supply of local services, such as schools, public transportation options, health care facilities, dining options, jobs, recreation areas, and retail stores, by creating local areas that are sustainable, inclusive, and walkable within a small distance $[12,13]$. With this attention, some research suggests the need to plan and design pedestrian-scale neighbourhoods to improve local accessibility, adapt travel behaviours, and reduce car ownership and vehicle miles travelled [14,15]. For example, the idea of the 15-minute city is gradually growing in importance from both a policy and social perspective. The basis of the idea is the promotion of interventions to increase the supply of local services, such as schools, public transportation systems, health care facilities, dining facilities, jobs, recreation areas, and retail stores [16]. In this way, local areas are designed to be more sustainable, inclusive, and walkable within a small radius on foot or by bicycle. In this view, this idea aims to encourage the welfare of a community from the bottom up by proposing an alternative way of thinking about the optimal allocation of resources on a city scale [17]. In some studies, the 15-min idea has been used to assess the role of abandoned urban assets (e.g., large buildings and complexes and their areas) with the goal of ensuring broader social equality and access to key urban services for citizens [18]. ICT systems can also provide a contribution: for example, using mobile phone data it is possible to estimate origin-destination flows, local urban accessibility, and passenger boarding / alighting [19,20]. With reference to the above, Fig. 1 summarizes the concept of $15 \mathrm{~min}$ city with its four components/dimensions: (i) density, (ii) proximity, (iii) diversity and (iv) digitalization. In addition, the relationship with the transport system (mobility of people and goods) and the socio-economic system of an area is illustrated in Fig. 1.

In the 15-Minute City concept, density is considered in terms of people per square kilometre. In fact, in planning a sustainable city, it is considered essential to account for the optimal

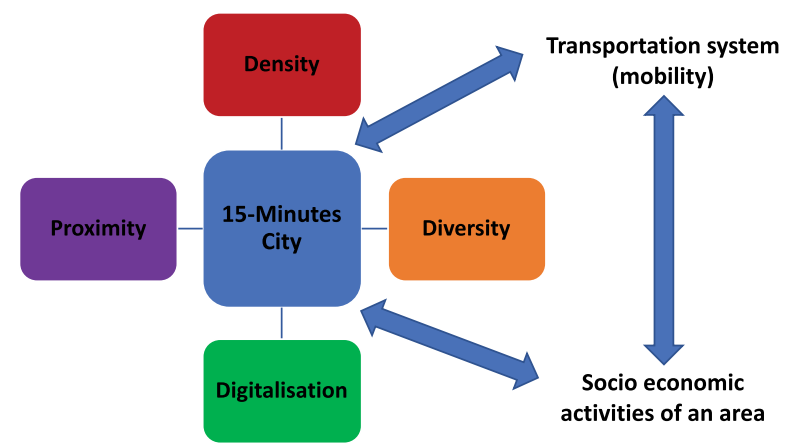

Figure 1: The 15-Minute City components and relationship with transportations system and socio-economic activities of an area (adapted from [16]). 
number of people in a specific area considering available services and resource consumption. Proximity is considered from both a temporal and spatial perspective. Within $15 \mathrm{~min}$, residents of a given neighbourhood can access different services. This dimension helps cities reduce the time lost in commuting and the environmental and economic impact that comes with it. Diversity has a dual function: on the one hand it relates to mixed-use neighbourhoods with residential, commercial, and entertainment components, and on the other it relates to diversity in culture and people. Finally, digitization is important to ensure the implementation of the other three dimensions. Using digital tools and solutions, it would be possible to ensure and improve services such as bike and car sharing rather than sensors and devices to ensure the safety of cyclists. Digitization also makes it possible to promote services such as online shopping, cashless transactions, etc.

Starting from these considerations, the aim of this work is to apply the idea of the city in 15 min to railway stations: in this perspective, the railway station becomes the starting point of the analysis as it represents the "door of the house", from where users start their last mile trips after getting off the train. In this way, infrastructure and transport policy are seen as a useful tool for increasing social cohesion and enhancing the integration of citizens in a territory [21]. For some railway stations located in northern Italy, an analytical index has been defined that summarizes the characteristics of the station in relation to the territory in which it is located. In this way, it is possible to classify the stations on the one hand and, on the other, to identify and propose improvements aimed at relaunching the role of a railway station in a territory. This work represents a preliminary study to begin to address the issue related to the centrality of railway stations in the development of an urban area.

\section{METHODOLOGY}

The proposed model provides, for each station, the calculation of a dimensionless index $I S$ Index Station that identifies how much a generic station is integrated in a territorial context. The higher the value of $I S$ is, the more the station is located close to various useful services for the community: it follows that the station is also more accessible. The approach adopted is comparative: this means that the value of the index is not in itself of absolute importance, but it is necessary to compare the indices of different railway stations in order to carry out evaluations over a territory [22]. From this point of view, the proposed model represents a useful decision support tool that can be used both by agencies and institutions in charge of mobility and territory planning and by station managers. The calculation of $I S$ for each station allows on the one hand to identify and implement any interventions to improve the relationship between a station and the territory and on the other to support the design process of a new station in function of what is around. The proposed model is simple and flexible in that some parameters can be customized to the analyst's specific needs. In addition, the model can be replicated in other contexts as it does not require hard-to-find data and information. Finally, the structure of the model makes it expandable with possible other indicators that will be able to be added according to the type of analysis to carry out. An interesting aspect of the model consists in being able to represent and to compare the various indicators that constitute the $I S$ : in this way the analyst has a complete vision of like it comes determined $I S$ and which can be the aspects to improve. Figure 2 shows the methodological framework divided into three steps.

The Index Station $(I S)$ calculation follows a linear approach in which several indicators associated with the services present in an area are considered. Each indicator is multiplied by a relative weight. In eqn (1) is the analytical formulation of $I S$ : 


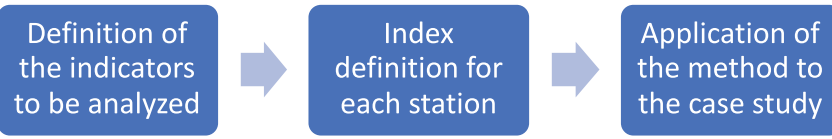

Figure 2: 3-step methodological framework.

$$
I S_{s}=a * I N D_{-} 1_{s}+b * I N D_{-} 2_{s}+c * I N D_{-} 3_{s}+\ldots+d * I N D_{-} N_{s},
$$

where:

- $a, b, c$ and $d$ are relative weights associated with each indicator. In this way it is possible to consider whether some indicators are more important than others;

- IND_1, IND_2,$I N D \_3$ are the indicators associated with the different services (service 1 , service 2 and service 3 ) located around a station $s$.

The calculation of the indicators considers the distance of the various services from the railway station in order to estimate accessibility. Specifically, three possible temporal distances from the station are identified within which to evaluate the presence of a service in the area. In fact, a service that is closer to a station could be more important than one that is further away and can be reached in a longer time. For example, two stations $A$ and $B$ have the same number and type of services, but in the case of station $A$ all services can be reached in 5 min and in the case of station $B$ they can be reached in $15 \mathrm{~min}$ : it follows that station $A$ is more integrated into the territory than station $B$. Having said this, the proposed method involves calculating each indicator in the following way:

$$
I N D_{-} n_{s}=\alpha^{*} n s_{t 1}+\beta^{*} n s_{t 2}+\gamma^{*} n s_{t 3},
$$

where:

- $\alpha, \beta$, and $\gamma$ represent relative weights with respect to each time distance from station $s$. For example, a service located closer to a station has a higher weight than one located farther away;

- $n s_{\mathrm{t} 1}$ : represents the number of services within the time distance $t_{1}$ from the station $s$;

- $n s_{12}$ : represents the number of services within the time distance $t_{2}$ from the station $s$;

- $n s_{\mathrm{t} 3}$ : represents the number of services within the time distance $t_{3}$ from the station $s$.

\section{CASE STUDY IN LOMBARDY REGION}

After defining the analytical method, an application was performed to a case study including four railway stations located in the Lombardy Region. The chosen stations, managed by RFI - Rete Ferroviaria Italiana, represent four different realities: (i) city neighbourhood - Milano Porta Vittoria, (ii) hinterland neighbourhood - Gallarate, (iii) touristic destination - Desenzano del Garda, (iv) town centre - Monza as shown in Fig. 3. 


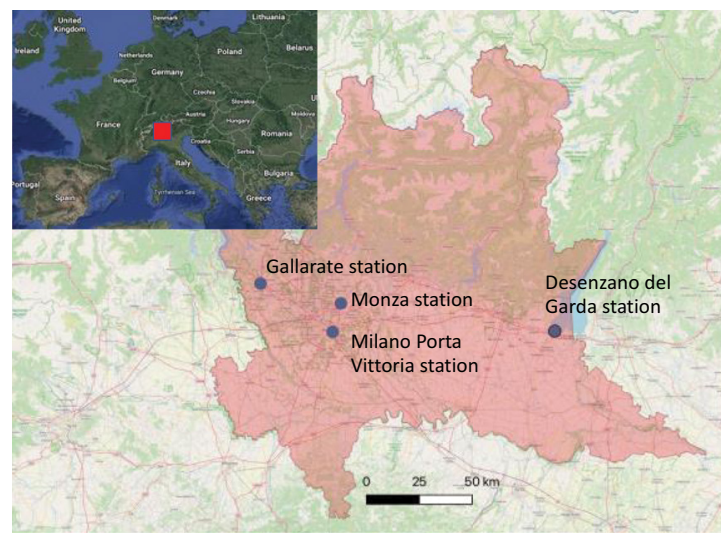

Figure 3: Location of the four analysed stations (data source: www.openstreetmap.org).

For the calculation of the Index Station, seven indicators associated respectively with seven types of services located around each station were defined. The following eqn (3) shows the analytical formulation of $I S$ with the respective indicators:

$$
I S_{s}=a * A C C_{s}+b * S P O_{s}+c * C U L_{s}+d * E D U_{s}+e^{*} F I N_{s}+f * H E A_{s}+g * M A R_{s},
$$

where:

- $A C C_{\mathrm{s}}$ : indicator related to the accommodation service;

- $S P O_{\mathrm{s}}$ : indicator related to the sport service;

- $C U L_{\mathrm{s}}$ : indicator related to the culture service;

- $E D U_{\mathrm{s}}$ : indicator related to the education service;

- $F I N_{\mathrm{s}}$ : indicator related to the financial service;

- $H E A_{\mathrm{s}}$ : indicator related to the healthcare service;

- $M A R_{\mathrm{s}}$ : indicator related to the market service.

With reference to the relative weights $a, b, c, d, e, f$ and $g$ have been assumed in this analysis equal to 1 . Currently, it has been preferred not to define priorities among the various services identified. Subsequent evaluations will be able to suggest how to diversify the relative weights also in function of the territorial context. As far as eqn (3) is concerned, the adopted values are reported in Table 1.

Basically, three areas were defined around each station considering isochrones equal to $t_{1}=5 \mathrm{~min}, t_{2}=10 \mathrm{~min}$ and $t_{3}=15 \mathrm{~min}$. Using GIS (Geographic Information System) tools, the polygons associated with the different services considered were identified. Finally, for each service (polygon) the fastest route connecting it with the railway station was determined as shown in Fig. 4.

For each railway station examined, an analysis of passenger data was carried out in order to find out the volumes and, therefore, the relevance of the station itself where the passenger service is provided. The analysis was carried out in three temporal situations: weekday, Saturday, holiday as shown in Fig. 5.

The following are the results obtained for the four railway stations analysed. 
Table 1: Values adopted in the case study.

\begin{tabular}{lllllll}
\hline Parameter & $t_{1}$ & $t_{1}$ & $t_{1}$ & $\alpha$ & $\beta$ & $\gamma$ \\
\hline Adopted value & $5 \mathrm{~min}$ & $10 \mathrm{~min}$ & $15 \mathrm{~min}$ & 0.5 & 0.33 & 0.17 \\
\hline
\end{tabular}

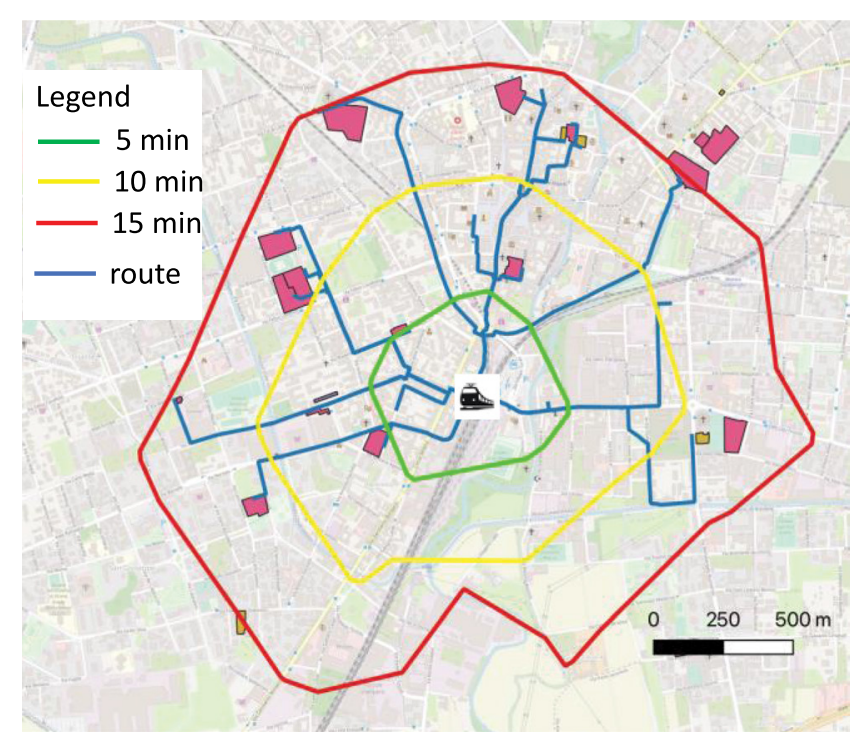

Figure 4: Representation of the three isochrones, the services on the territory (polygons) and the routes connecting the services to the station (data source: https://www.openstreetmap.org).

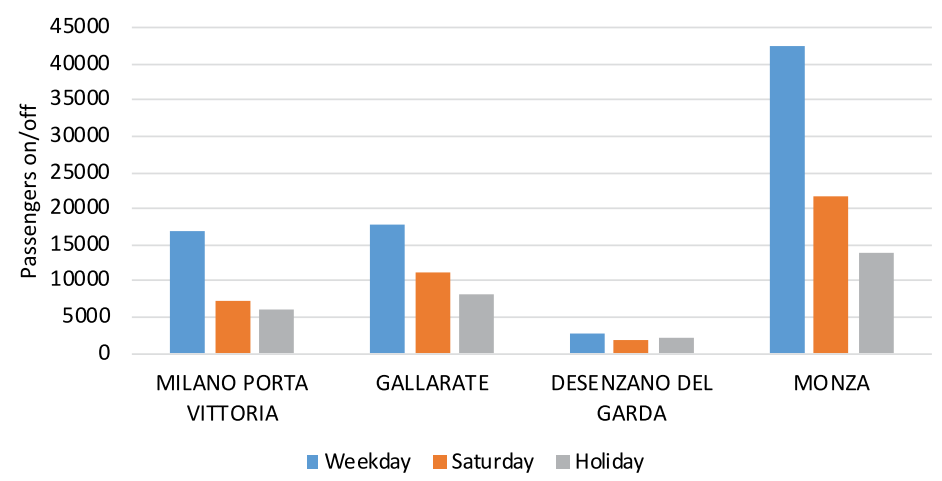

Figure 5: Number of passengers on and off for the four stations analysed.

\subsection{Milano - Porta Vittoria station}

Milano Porta Vittoria is a station of the Milano Passante Ferroviario and is located in the eastern part of the city. Lines S1, S2, S5, S6, S12 and S13 of the suburban rail service pass through the station. Figure 6 shows the number of services for each of the seven indicators used in the analysis. 


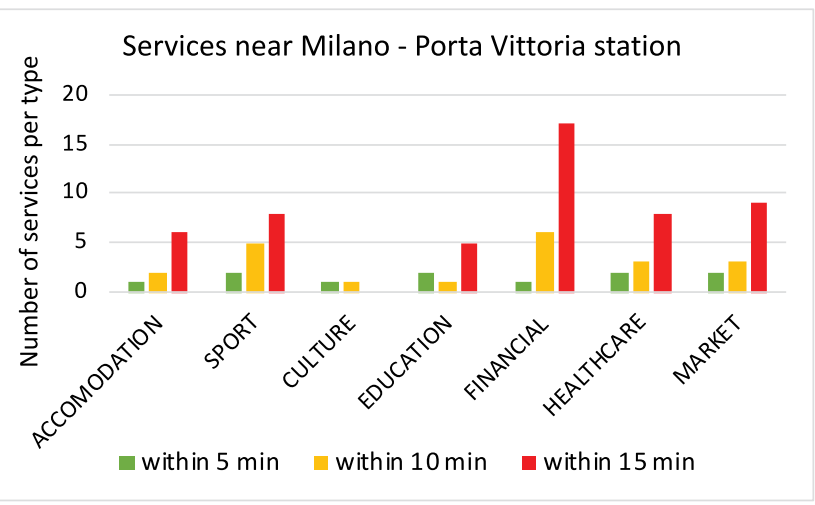

Figure 6: Number of services related to the seven indicators used for the analysis of Porta Vittoria station. Each service is evaluated considering the three isochrones (temporal distances) equal to 5, 10 and $15 \mathrm{~min}$.
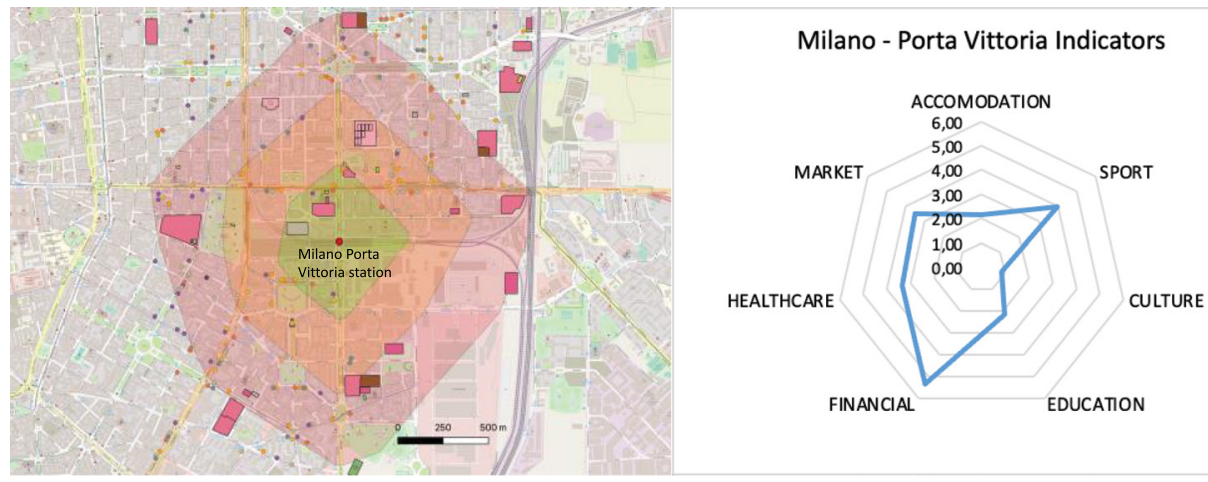

Figure 7: Mapping of services and numerical representation of the seven indicators calculated for the Porta Vittoria station.

Mapping of services and the calculated value for each indicator is represented in Fig. 7. The indicator with the highest value is financial (5.33) while the value of $I S$ is equal to 21.33.

\subsection{Gallarate station}

Gallarate is the railway station located in the homonymous town on the Domodossola-Milano line, from which the lines to Varese and Laveno - Mombello branch off. Figure 8 shows the number of services for each of the seven indicators used in the analysis.

Mapping of services and the calculated value for each indicator is represented in Fig. 9. Also in this case, the indicator with the highest value is the financial one (6.5), while the other indicators are considerably lower. The $I S$ value is equal to 22.33 .

\subsection{Desenzano del Garda station}

Desenzano del Garda - Sirmione is a railway station on the Milano - Venice line. It serves the two towns of the same name: Desenzano del Garda, where it is located, and Sirmione, 


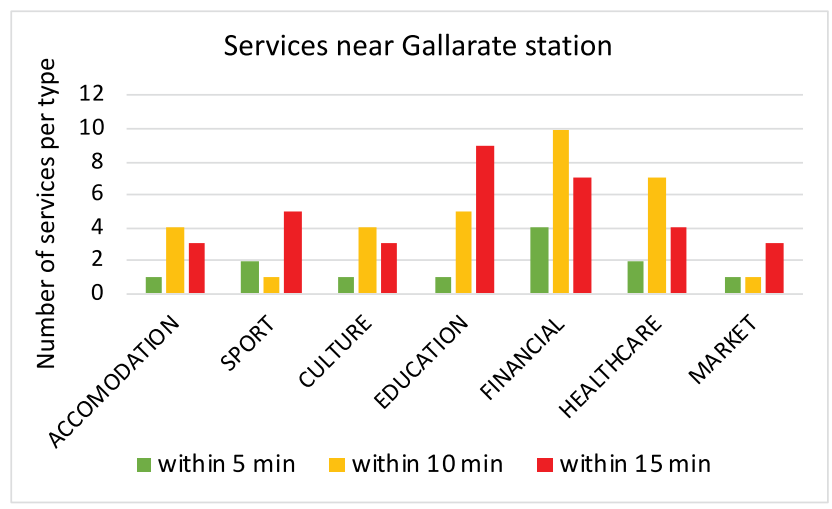

Figure 8: Number of services related to the seven indicators used for the analysis of Gallarate station. Each service is evaluated considering the three isochrones (temporal distances) equal to 5,10 and $15 \mathrm{~min}$.

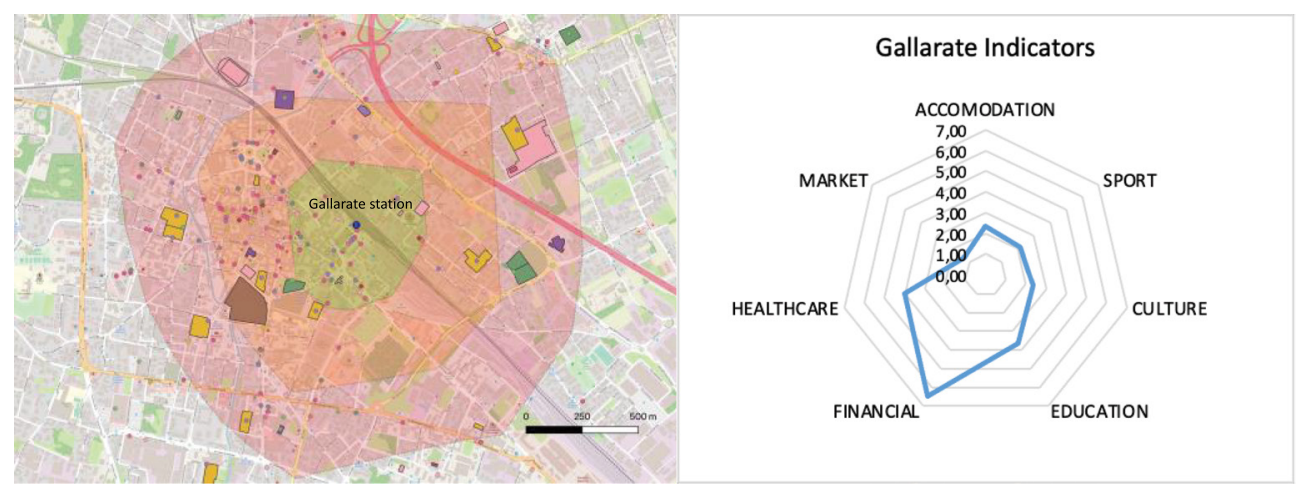

Figure 9: Mapping of services and numerical representation of the seven indicators calculated for the Gallarate station.

which can be reached via the interurban Brescia - Verona line. Figure 10 shows the number of services for each of the seven indicators used in the analysis.

Mapping of services and the calculated value for each indicator is represented in Fig. 11. As might be expected, in this case the indicator with the highest value is the accommodation one (3.67), as this is a predominantly tourist railway station. The other indicators have very low values. Finally, the $I S$ value is 7.83 .

\subsection{Monza station}

Monza is the main railway station of the city of Lombardia and represents the main railway junction of the Brianza area. The station is located at the junction of the Milano - Chiasso and Milano - Lecco lines, and is the origin of the line to Lecco via Molteno. Figure 12 shows the number of services for each of the seven indicators used in the analysis. 


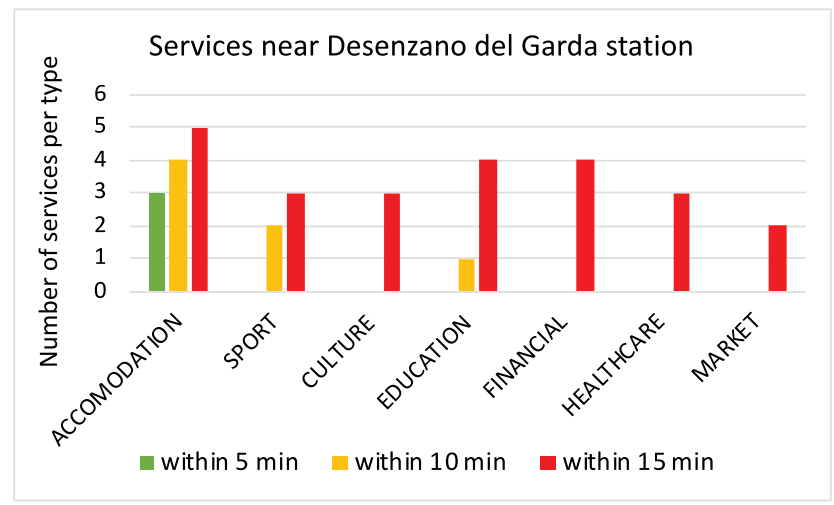

Figure 10: Number of services related to the seven indicators used for the analysis of Desenzano del Garda station. Each service is evaluated considering the three isochrones (temporal distances) equal to 5, 10 and $15 \mathrm{~min}$.

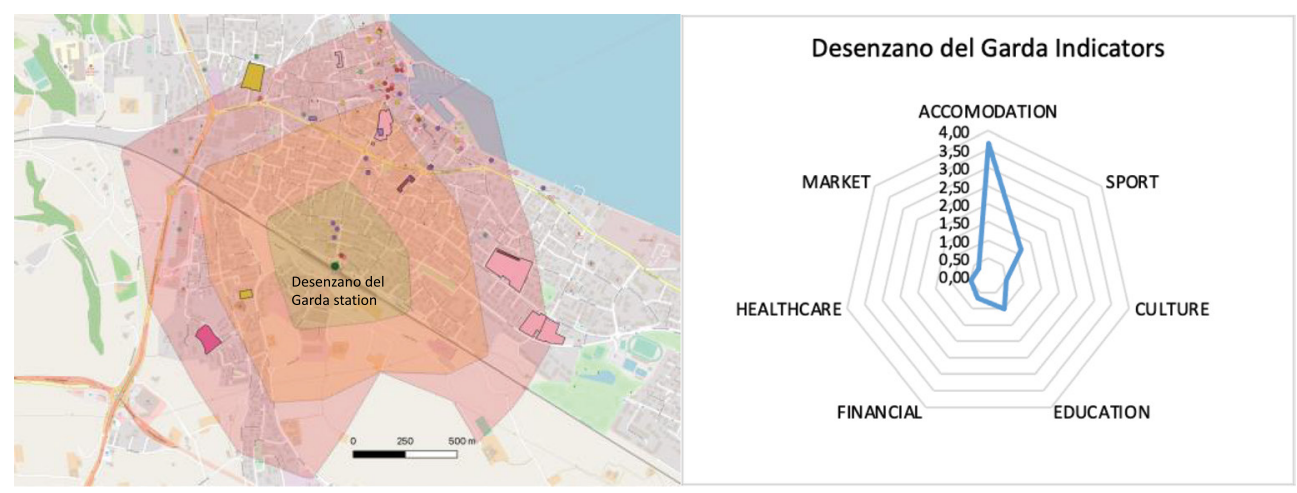

Figure 11: Mapping of services and numerical representation of the seven indicators calculated for the Desenzano del Garda station.

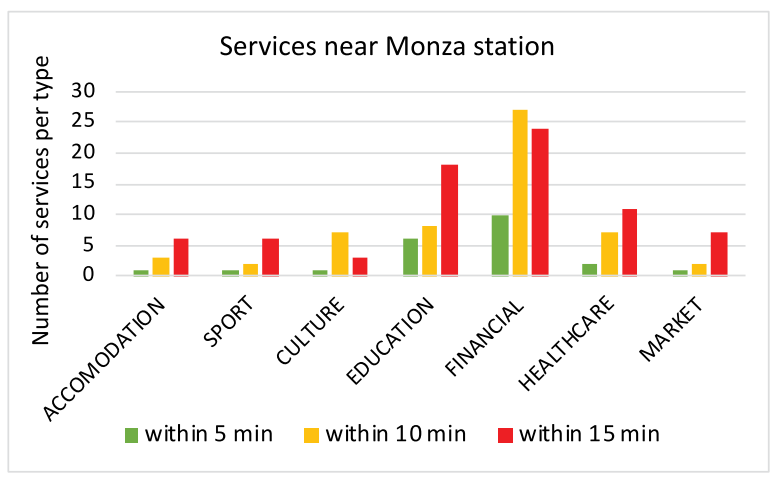

Figure 12: Number of services related to the seven indicators used for the analysis of Monza station. Each service is evaluated considering the three isochrones (temporal distances) equal to 5, 10 and 15 min. 
Mapping of services and the calculated value for each indicator is represented in Fig. 13. Also in this last case, the indicator with the highest value is the financial one, while the other indicators are considerably lower. The second highest indicator is education (8.67). The IS value is 42.17 .

\subsection{Summary of results}

In order to compare the results of the analysis, Fig. 14 shows a summary of the $I S$ for the four stations under study. Among the four realities analysed, it emerges that the Monza station is characterized by the highest value while Desenzano del Garda by a lower $I S$. These results were obtained without considering the importance of the seven indicators (relative weights equal to 1$)$.

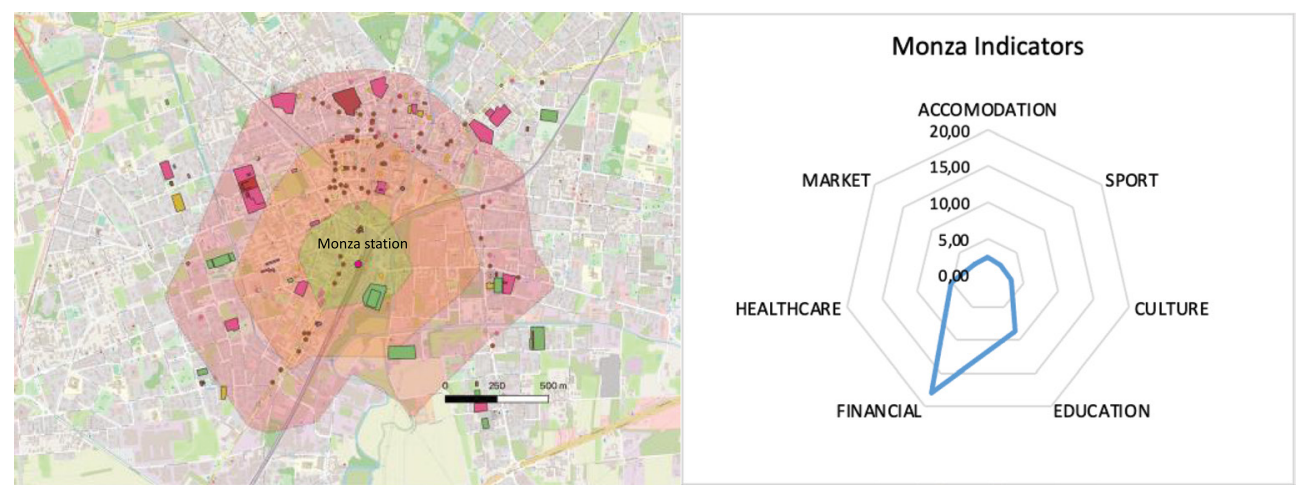

Figure 13: Mapping of services and numerical representation of the seven indicators calculated for the Monza station.

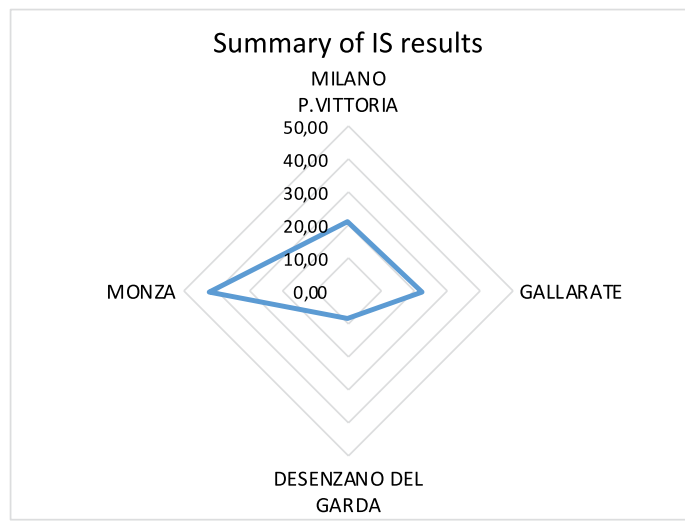

Figure 14: IS value comparison for the four analysed railway stations. 


\section{CONCLUSIONS}

This paper proposes an operative and simple methodology for the analysis of the relationship between territory and railway station. An analytical method is defined that allows to calculate for each station the $I S$ as a function of several indicators. The higher the value of $I S$ is, the more the station is located close to various useful services for the community: it follows that the station is also more accessible. The approach adopted is comparative: this means that the value of the index is not in itself of absolute importance, but it is necessary to compare the indices of different railway stations in order to carry out evaluations over a territory and define the priorities. From this point of view, the proposed model represents a useful decision support tool that can be used both by agencies and institutions in charge of mobility and territory planning and by station managers.

The model has been applied to a case study in Lombardy Region (Italy) where four representative railway stations have been chosen: (i) city neighbourhood - Milano Porta Vittoria, (ii) hinterland neighbourhood - Gallarate, (iii) touristic destination - Desenzano del Garda, (iv) town centre - Monza. Using GIS tools and spreadsheets, seven indicators and the IS were determined. Further development of the research could be oriented towards the identification of new indicators relating to services in an area. Finally, evaluations can be carried out regarding the choice of relative weights used in the proposed model: this will allow the analyst to have greater awareness of the results obtained. A multistakeholder multicriteria analysis would be important to take into account the priorities of different actors [23].

\section{REFERENCES}

[1] European Commission, Directorate-General for Mobility and Transport, Sustainable Urban Mobility: European Policy, Practice and Solutions, European Union, Catalogue Number MI-02-16-275-EN-N, ISBN 978-92-79-66651-3, 2017. DOI 10.2832/51274.

[2] Batty, M., Besussi, E., Chin, N., Traffic, urban growth and suburban sprawl. CASA. 2003.

[3] Brueckner, J.K., Urban sprawl: diagnosis and remedies. International regional science review, 23 (2):160-171, 2000. https://doi.org/10.1177/016001700761012710.

[4] Glaeser, E.L., Kahn, M.E., Sprawl and urban growth. In: Handbook of regional and urban economics. vol. 4. Elsevier; p. 2481-2527, 2004.

[5] Bento A.M., Cropper, M.L., Mobarak, A.M., Vinha, K., The effects of urban spatial structure on travel demand in the United States. Review of Economics and Statistics, 87(3), 466-478, 2005. https://doi.org/10. 1162/0034653054638292.

[6] Anderson, W.P., Kanaroglou, P.S., Miller, E.J., Urban form, energy and the environment: a review of issues, evidence and policy. Urban studies, 33(1), 7-35, 1996. https://doi. org/10.1080/00420989650012095.

[7] Gordon, P., Kumar, A., Richardson, H.W., The influence of metropolitan spatial structure on commuting time. Journal of urban economics, 26(2), 138-151, 1989. https://doi. org/10.1016/0094-1190(89) 90013-2.

[8] Muñiz, I., Galindo, A., Urban form and the ecological footprint of commuting. The case of Barcelona. Ecological Economics, 55(4), 499-514, 2005. https://doi.org/10.1016/j. ecolecon.2004.12.008.

[9] Ewing, R., Hamidi, S., Compactness versus sprawl: a review of recent evidence from the United States. Journal of Planning Literature, 30(4), 413-432, 2015. https://doi. org/10.1177/0885412215595439. 
[10] Kirkley, A, Barbosa, H, Barthelem, Y.M, Ghoshal, G., From the betweenness centrality in street networks to structural invariants in random planar graphs. Nature communications, 9(1), 1-12, 2018. https://doi.org/10.1038/s41467-018-04978-z.

[11] Brezzi, M., Veneri, P., Assessing polycentric urban systems in the OECD: country, regional and metropolitan perspectives. European Planning Studies, 23(6), 1128-1145, 2015. https://doi.org/10.1080/09654313.2014.905005.

[12] Veneri, P., Urban spatial structure in OECD cities: is urban population decentralising or clustering? Organisation for Economic Cooperation and Development, Paris; 2015.

[13] Artmann, M, Kohler, M, Meinel, G, Gan, J, Ioja, IC., How smart growth and green infrastructure can mutually support each other: a conceptual framework for compact and green cities. Ecological Indicators, 96, 10-22, 2019.

[14] Krizek, KJ., Residential relocation and changes in urban travel: does neighborhoodscale urban form matter? Journal of the American Planning Association. 69(3), 265281, 2003. https://doi.org/10.1080/01944360308978019.

[15] Zhang, W., Zhao, Y., (Jason) Cao, X., Lu, D., Chai, Y., Nonlinear effect of accessibility on car ownership in Beijing: pedestrian-scale neighborhood planning. Transportation Research Part D: Transport and Environment, 86(December 2019), 102445, 2020. https://doi.org/10.1016/j.trd.2020.102445.

[16] Moreno, C., Allam, Z., Chabaud, D., Gall, C., Pratlong, F., Introducing the " 15 -minute city": sustainability, resilience and place identity in future post-pandemic cities. Smart Cities, 4(1) 93-111, 2021. https://doi.org/10.3390/smartcities4010006.

[17] Pozoukidou, G., Chatziyiannaki, Z., 15-minute city: decomposing the new urban planning eutopia. Sustainability, 13, 928, 2021. https://doi.org/10.3390/su13020928.

[18] Balletto, G., Ladu, M., Milesi, A., Borruso, G., A methodological approach on disused public properties in the 15-minute city perspective. Sustainability, 13, 593, 2021. https://doi.org/10.3390/su13020593.

[19] Graells-Garrido, E., Serra-Burriel, F., Rowe, F., Cucchietti, F.M., Reyes, P., A city of cities: measuring how 15-minutes urban accessibility shapes human mobility in Barcelona. PLoS ONE, 16(5), e0250080, 2021. https://doi.org/10.1371/journal. pone. 0250080

[20] Nitti, M., Pinna, F., Pintor, L., Pilloni, V., Barabino, B., Iabacus: a wi-fi-based automatic bus passenger counting system. Energies, 13(6), 2020. doi:10.3390/en13061446

[21] Coppola, P., Dell'Olio, L., Ibeas Portilla, A., Rediscovery the social role of transport infrastructures. Transportation Research Part A: Policy and Practice, 125, 169-170, 2019. doi:10.1016/j.tra.2018.10.007.

[22] Borghetti, F., Bozza, I., Maja, R., Malavasi, G., Ricci, S., Rizzetto, L., Unplanned rail service disruptions: recovery index for the station analysis where to set up a bus bridging. Ingegneria Ferroviaria, 75(11), 813-839, 2020.

[23] Gonzalez-Urango, H., Inturri, G., Le Pira, M., García-Melón, M., Planning for pedestrians with a participatory multicriteria approach. Journal of Urban Planning and Development, 146(3), (2020). doi:10.1061/(ASCE)UP.1943-5444.0000585. 